\title{
COVID-19 among Foreign Workers in Dormitories - How One Emergency Department Responded
}

\section{Dear Editor,}

Singapore saw its first COVID-19 case on 23 January 2020 , and one of the largest waves of infections presented itself in early March among foreign workers (FWs) who stay in dormitories. ${ }^{1}$ Most FWs live in purpose-built dormitories, which are self-sufficient communities with various amenities. Up to $12 \mathrm{FWs}$ are housed in each room, with shared bathrooms, toilets and common areas for dining and recreational activities. The unique nature of such a setting, with inadequate avenues for social distancing may have led to the rapid spread of COVID-19 among this population. ${ }^{2}$

Prompt and accurate diagnosis of COVID-19 has been crucial for management of cases through isolation, contact tracing and quarantine. ${ }^{3}$ In line with these strategies, the government of Singapore converted some dormitories into community isolation facilities, and placed them under lockdown to curb the spread of COVID-19. The FWs were isolated within the different blocks of the dormitories depending on their test results with those unwell assessed by medical personnel for further attention. ${ }^{4}$ Various measures requiring many resources to provide timely care for infected workers have helped prevent overwhelming the hospitals. ${ }^{5}$

The objectives of this paper are to document: (1) the internal response by the Sengkang General Hospital Emergency Department (ED) involving zone restriction, and external response involving the setting up of an on-site medical clinic and teleconsultation at the largest dormitory closest to it; (2) ED's response to manage FWs' attendance due to COVID-19 at the ED.

The ED belongs to a 1,000-bed tertiary hospital, and has an annual attendance of over 100,000 patients. The department utilises the Emergency Severity Index (ESI) to triage patients to different zones for management. ${ }^{6}$ Two dormitories are withing a $3 \mathrm{~km}$ radius of the hospital - one housing 13,000 FWs and is the largest cluster of COVID-19, and the other housing $6,800 \mathrm{FWs}^{4}$

This descriptive study was conducted by performing a medical record review of all FWs presenting to the ED between 1 January 2020 and 31 July 2020.
Demographics, triage category, diagnosis, disposition, and length of stay (defined as registration time to disposition time) were collected in a standardised form and analysed. Only FWs who resided in dormitories were included. An exemption was obtained from the institutional review board for this study (CIRB Ref: 2020/2500).

Statistical analysis was performed using SPSS version 25 (SPSS, Chicago, US). Categorical and continuous data were presented as frequencies with percentages, and median with interquartile range respectively.

At the start of the pandemic, patients were screened at the entrance of the ED for fever, upper respiratory tract symptoms, recent travel, and other high-risk criteria as defined by the Ministry of Health, Singapore $(\mathrm{MOH})$. In response to the outbreak of COVID-19 in dormitories, changes were made to the screening process in accordance with the criteria issued by $\mathrm{MOH}$. As part of the internal response to the increasing number of FWs presenting to the ED, the internal ED zones were re-arranged and divided into high-risk (red), intermediate-risk (yellow) and low-risk zones (green $)^{7}$ to minimise transmission especially from active COVID-19 clusters (Table 1).

As part of the external response, the hospital led the setting up of an on-site clinic at the most populous dormitory situated nearest to it, led by a team comprising 1 Emergency Physician (EP) and 2 nurses who attended to the medical needs of all FWs there. The team had basic medical supplies, common medications, managed the on-site clinic as a primary care facility and reviewed FWs who reported sick. Any patient deemed to require further management in an acute hospital was conveyed to the hospital, either via a designated non-emergency ambulance (for stable cases) or via the Emergency Medical Services for unstable cases.

A teleconsultation service was set up to support the dormitory's needs outside clinic hours for all FWs. The dormitory operator contacted the ED team via a designated smartphone, and the EP on shift assessed the FWs via video call. If the patient's condition was deemed stable by the EP, the FW was asked to wait in the 
Table 1. Internal ED Layout before and during the COVID-19 pandemic

\begin{tabular}{|c|c|c|c|}
\hline Zone & Pre-COVID-19 & During COVID-19 & Risk of COVID-19 \\
\hline $\begin{array}{l}\text { Isolation } \\
\text { ( } 6 \text { negative pressure rooms) }\end{array}$ & $\begin{array}{l}\text { Suspected infectious diseases patients (e.g. } \\
\text { tuberculosis, hand-foot-and mouth disease) }\end{array}$ & $\begin{array}{l}\text { High-risk and confirmed COVID-19 } \\
\text { cases from the community, and other } \\
\text { infectious diseases patients }\end{array}$ & High-Red \\
\hline Acute Care & ESI 4 and ESI 5 patients & $\begin{array}{l}\text { FWs from the dormitories } \\
\text { (COVID/non-COVID) }\end{array}$ & High-Red \\
\hline South Zone & $\begin{array}{l}\text { ESI } 2 \text { and ESI } 3 \text { patients } \\
\text { (conveyed by ambulances) }\end{array}$ & $\begin{array}{l}\text { ESI } 2 \text { and ESI } 3 \text { patients } \\
\text { (with ARI symptoms) }\end{array}$ & Intermediate- Yellow \\
\hline North Zone & $\begin{array}{l}\text { ESI } 2 \text { and ESI } 3 \text { patients } \\
\text { (ambulatory/self-conveyed) }\end{array}$ & $\begin{array}{l}\text { ESI } 2 \text { and ESI } 3 \text { patients } \\
\text { (without ARI symptoms) }\end{array}$ & Low-Green \\
\hline
\end{tabular}

ARI: acute respiratory infection; ESI: Emergency Severity Index; P-Zone: Paediatrics Zone

*All FWs, if triaged as ESI 1 or ESI 2 and needed immediate resuscitation/closer monitoring.

dormitory for a follow up at the on-site clinic. If there were concerns about the clinical condition of the FW, he was sent to the ED for further assessment.

There was an increase in attendance by the FWs from dormitories at the ED between January and April 2020. The on-site clinic was set up in the 2 nd week of April 2020 in response. Thereafter, there was a sharp decline in attendance at the ED (Fig. 1).

Acuity of the medical complaints by the FWs was low (P2 and P3), and they were mainly non-trauma related (Table 2). The top 3 acute respiratory infection
(ARI)-related diagnoses were COVID-19: 331 (19.1\%), upper respiratory tract infection: 159 (9.2\%) and pneumonia: $17(1.0 \%)$. The top 3 non-ARI related diagnosis were unspecified chest pain: $113(6.5 \%)$, dengue: 89 (5.1\%) and renal colic: $54(3.1 \%)$.

Owing to the proximity of this ED to the dormitory with the largest cluster, it was one of the first to encounter this unique situation. Our data shows that the number of FWs presenting to the ED reduced after the initiation of the on-site clinic. The number of FWs presenting to the on-site clinic increased as the lockdown

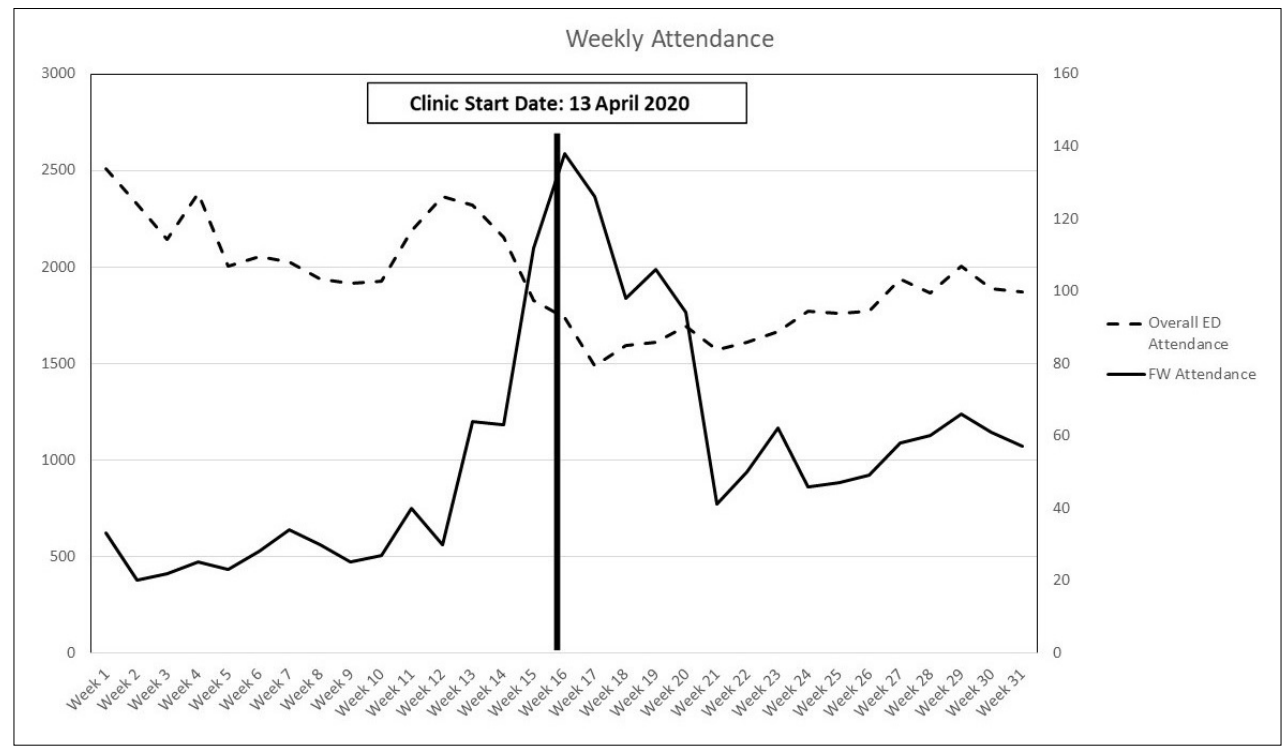

Fig. 1. Overall and FWs' ED attendance between January and July 2020

ED: emergency department; FW: foreign worker 
Table 2. Demographics of FWs, modes of conveyance, acuity and case types presented to the ED from January to July 2020

\begin{tabular}{|c|c|}
\hline Characteristics & n (\%) \\
\hline Median age (Interquartile range), in years & $34(28$ to 43$)$ \\
\hline Male, n (\%) & $1735(100)$ \\
\hline \multicolumn{2}{|l|}{ Nationality, n (\%) } \\
\hline Bangladesh & $670(38.6)$ \\
\hline India & $421(24.3)$ \\
\hline Malaysia & $313(18.0)$ \\
\hline China & $216(12.4)$ \\
\hline Myanmar & $38(2.2)$ \\
\hline Thailand & $26(1.5)$ \\
\hline Others & $51(2.9)$ \\
\hline \multicolumn{2}{|l|}{ Conveyance to ED } \\
\hline Self, n (\%) & $886(51.0)$ \\
\hline Non SCDF ambulance, n (\%) & $633(36.5)$ \\
\hline SCDF ambulance, $\mathrm{n}(\%)$ & $216(12.4)$ \\
\hline \multicolumn{2}{|l|}{ Acuity $^{*}$} \\
\hline P1, n (\%) & $46(2.7)$ \\
\hline $\mathrm{P} 2, \mathrm{n}(\%)$ & $661(38.1)$ \\
\hline P3, n (\%) & $981(56.5)$ \\
\hline \multicolumn{2}{|l|}{ Case Type } \\
\hline Non-trauma, n (\%) & $1545(89.0)$ \\
\hline Trauma, n (\%) & $190(11.0)$ \\
\hline \multicolumn{2}{|l|}{ Diagnosis } \\
\hline Non-ARI-related, n (\%) & $1204(69.4)$ \\
\hline ARI-related, n (\%) & $531(30.6)$ \\
\hline \multicolumn{2}{|l|}{ Disposition } \\
\hline Admitted to hospital, n (\%) & $723(41.7)$ \\
\hline ARI-related admissions, n (\%) & $324(44.8)$ \\
\hline Mortality, n (\%) & $3(0.2)$ \\
\hline COVID-related mortality ${ }^{\dagger} \mathrm{n}(\%)$ & $1(0.06)$ \\
\hline
\end{tabular}

ARI: acute respiratory infection; SCDF: Singapore Civil Defence Force

* There was missing acuity data for $47(2.7 \%)$ patients.

One FW who was positive for COVID-19 died of a ruptured myocardial infarction.

continued. This suggests that all the FWs from this dormitory who required medical attention would have had to be conveyed to the hospital, if the on-site clinic was not deployed.

Most of the FWs eventually presenting to the hospital and the on-site clinic had non-ARI related diagnoses (Fig. 2). The number of ARI-related admissions, which were at high risk for possible COVID-19 were lower than non-ARI admissions, suggesting that despite being from an active COVID-19 cluster, the number of FWs with non-ARI diagnosis who required inpatient management was high.
Helman et al. described 4 main strategies for EDs to increase capacity during the surge of the COVID-19 pandemic. These included (1) decreasing demand, (2) establishing alternate care facilities, (3) minimising resource consumption by admitted patients and (4) expanding bed capacity. ${ }^{8}$ The interventions of setting up the on-site clinic and the teleconsultation service were directly in line with the first two strategies of decreasing demand and establishing alternate care facilities.

FWs staying in dormitories are work-permit holders, presumed to have a certain level of fitness before being hired. As per labour laws in Singapore, a foreign worker requires a medical examination before being issued a work permit. ${ }^{9}$ Most of the FWs who eventually attended the ED had medical problems of lower acuity (possibly due to the lack of significant comorbidities), thus requiring minimal medical interventions. During nonCOVID times, these FWs might have first presented to the primary care facilities such as polyclinics or general practitioner (GP) clinics. However, following lockdown at the dormitories, the FWs were not allowed to visit GP clinics. The on-site clinic addressed this by functioning as a GP clinic, thus preventing overwhelming conveyance to the ED. This ensured the ED staff were available to attend to emergencies such as incidences of stroke or severe pneumonia.

Even before the pandemic, studies have shown that clinical consultations conducted remotely via video are associated with high satisfaction, no difference in disease progression, and lower costs compared to face-to-face consultations. ${ }^{10}$ Hong et al. described their experience with telemedicine during the COVID-19 pandemic in Western China, and observed benefits in both diagnosis and therapy of patients with COVID-19. ${ }^{11}$ This ED's experience has shown that it is possible to carry out teleconsultation in a safe and controlled way to ensure optimal use of resources. The use of teleconsultation also allowed pre-triage to be performed, and ensured that the ED team could be prepared in advance, should a patient require a transfer to the hospital.

The ED's internal response ensured safety of the staff as well as other patients from the community. To date, no healthcare worker in Singapore (in this ED and the dormitory) has been diagnosed with COVID-19 in the course of their work, and this may have been made possible by staff vigilance, clear segregation of the ED into the different zones, emphasis on use of appropriate personal protective equipment and staff welfare. ${ }^{12-14}$

As this is a single-center study, the results may not be generalisable across all communities and population. 


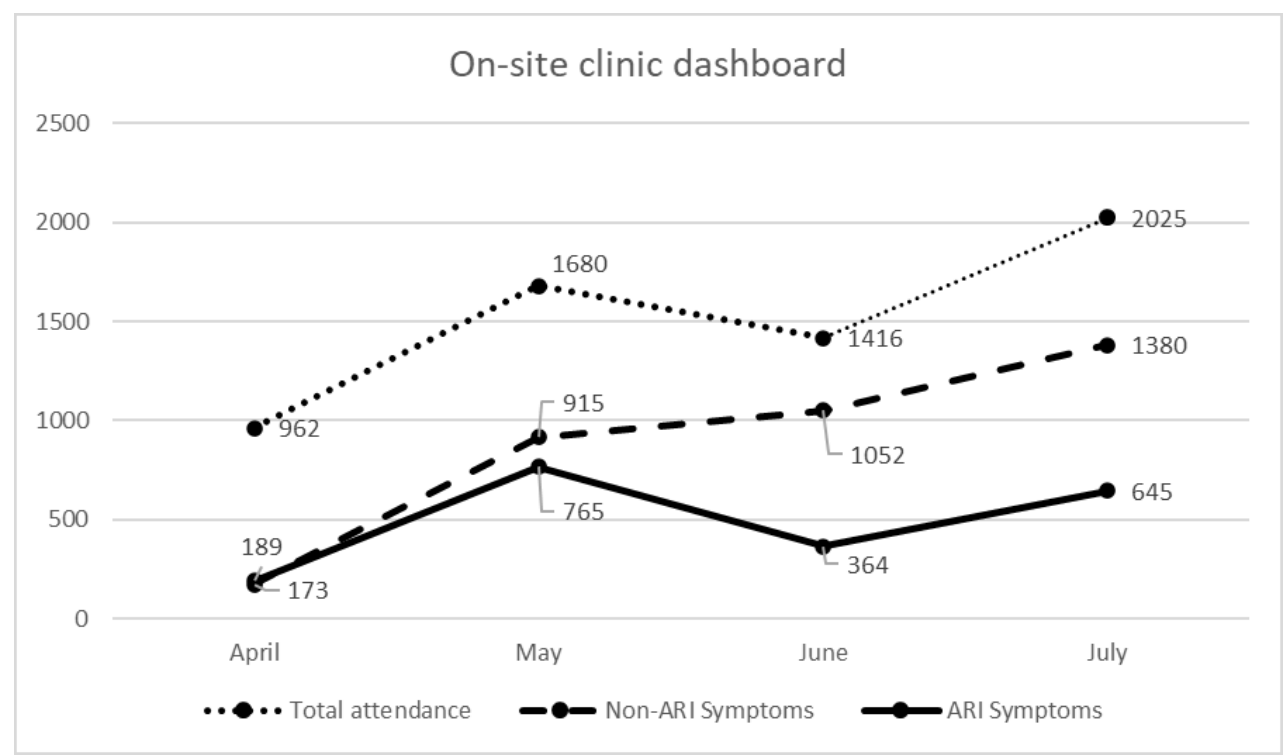

Fig. 2. Total on-site clinic attendances and number of patients seen for ARI/non-ARI symptoms per month ${ }^{*}$ ARI: acute respiratory infection

* As the on-site clinic was deployed on 13 April 2020, data for April spans a 2-week period. Non-ARI related complaints were predominant. The number of FWs seen at clinic/day: 62 (45-97). Median referrals to ED/ day: 2 (1-3). Median teleconsultations/day: $1(0-2)$.

The retrospective nature of the study also prevents assessment of other factors that may have contributed to the success of the ED's response, notably, the nationwide lockdown between the months of April and May 2020 that may have reduced the FWs attendance at the ED. The medical team had also only supported 1 dormitory, and approximately $50 \%$ of the FWs who attended the ED were self-conveyed. This suggests that a considerable number of the FWs had presented to the ED prior to the dormitories being gazetted as isolation zones (between January and March 2020), also from the other dormitories that were not overseen by the medical team.

The setting up of the on-site clinic and teleconsultation service helped to mitigate the spread of COVID-19 from the dormitories to the community, while ensuring that this vulnerable group still had access to basic medical care. Within the ED, which was still seeing patients from the community, it was important to recognise this highrisk group and establish measures such as segregation, to prevent community spread. Overall, these responses have contributed to safety of the FWs, allowed better containment of COVID-19, and ensured staff and patient safety within the department.

\section{REFERENCES}

1. Ministry of Health, Singapore. 12 More Cases Discharged; 47 New Cases of COVID-19 Infection Confirmed, 31 March 2020. Available at: https://www.moh.gov.sg/news-highlights/details/12-more-cases- discharged-47-new-cases-of-covid-19-infection-confirmed. Accessed on 17 September 2020.

2. Ministry of Health, Singapore. Delivered Remarks by Manpower Minister Josephine Teo at MTF Press Conference on 14 April 2020. Available at: https://www-moh-gov-sg-admin.cwp.sg/docs/ librariesprovider5/2019-ncov/delivered-remarks-by-manpowerminister-josephine-teo-at-mtf-press-conf-14-apr-2020.pdf. Accessed on 17 September 2020.

3. Koh D, Cunningham AC. Counting Coronavirus Disease 2019 (COVID-19) Cases: Case definitions, screened populations and testing techniques matter. Ann Acad Med Singap 2020;49:161-165.

4. Ministry of Health, Singapore. Additional Measures to Minimise Further Spread of COVID-19 within Foreign Worker Dormitories, 5 April 2020. Available at: https://www.moh.gov.sg/news-highlights/ details/additional-measures-to-minimise-further-spread-of-covid-19within-foreign-worker-dormitories. Accessed on 17 September 2020.

5. Lim TK. The facts, fallacies and uncertainties about Coronavirus Disease 2019 (COVID-19). Ann Acad Med Singap 2020;49:343-345.

6. Agency for Healthcare Research and Quality. Emergency Severity Index (ESI): A triage tool for emergency departments, May 2020. Available at: https://www.ahrq.gov/professionals/systems/hospital/esi/ index.html. Accessed on 17 September 2020.

7. Tan RMR, Ong GY, Chong SL, et al. Dynamic adaptation to COVID-19 in a Singapore paediatric emergency department. Emerg Med J. 2020;37:252-254.

8. Helman, A. Kollek, D. ED Surge Capacity Strategies in the COVID-19 Pandemic, Emergency Medicine Cases, 23 March 2020. Available at: https://emergencymedicinecases.com/surge-capacitystrategies-covid-19. Accessed on 17 September 2020.

9. Ministry of Manpower, Singapore. Services sector: Work Permit requirements, 11 June 2020. Available at: https://www.mom.gov.sg/ passes-and-permits/work-permit-for-foreign-worker/sector-specificrules/services-sector-requirements. Accessed on 17 September 2020. 
10. Greenhalgh T, Wherton J, Shaw S, et al. Video consultations for covid-19. BMJ. 2020;368:m998.

11. Hong $\mathrm{Z}, \mathrm{Li} \mathrm{N}$, Li D, et al. Telemedicine during the COVID-19 pandemic: Experiences from Western China. J Med Internet Res 2020;22:e19577.

12. Chew SY, Lee YS, Ghimiray D, et al. Characteristics and Outcomes of COVID-19 Patients with Respiratory Failure Admitted to a "Pandemic Ready" Intensive Care Unit - Lessons from Singapore. Ann Acad Med Singap 2020;49:434-48.

13. Shanker S, Chia DWJ, Ganti S. Difficulties faced by a medical team based at a COVID-19 quarantine facility. Singapore Med J 2020;10.11622/smedj.2020115. Accessed n 17 September 2020

14. Shi AH, Guo W, Chng CK, et al. Precautions When Providing Dental Care During Coronavirus Disease 2019 (COVID-19) Pandemic. Ann Acad Med Singap 2020;49:312-9.
Sameera Ganti, ${ }^{1}$ M.MED (Emergency Medicine), FRCEM (UK), FAMS (Singapore), Sanjeev Shanker, ${ }^{2} M B B C h$ BAO (Ireland), M.MED (Emergency Medicine), FAMS (Singapore),

Jen Heng $\underline{\text { Pek }},{ }^{1}$ MBBS (Singapore), MCEM (Singapore), M.MED (Emergency Medicine)

${ }^{1}$ Emergency Department, Sengkang General Hospital, Singapore ${ }^{2}$ Emergency Department, Woodlands Health Campus, Yishun Community Hospital, Singapore

Address for Correspondence: Dr Sameera Ganti, Emergency Department, Sengkang General Hospital, 110 Sengkang East Way, Singapore 544886. Email: ganti.sameera@singhealth.com.sg 